\title{
CXCL1-Triggered Interaction of LFA1 and ICAM1 Control Glucose-Induced Leukocyte Recruitment during Inflammation In Vivo
}

\author{
Kirsten Buschmann, Lutz Koch, Natascha Braach, Hanna Mueller, \\ David Frommhold, Johannes Poeschl, and Peter Ruef \\ Clinic of Neonatology, Department of Pediatrics, University of Heidelberg, 69120 Heidelberg, Germany \\ Correspondence should be addressed to Kirsten Buschmann, kirsten.buschmann@med.uni-heidelberg.de
}

Received 24 May 2012; Revised 16 August 2012; Accepted 23 August 2012

Academic Editor: Fulvio D’Acquisto

Copyright ( $) 2012$ Kirsten Buschmann et al. This is an open access article distributed under the Creative Commons Attribution License, which permits unrestricted use, distribution, and reproduction in any medium, provided the original work is properly cited.

\begin{abstract}
It is well acknowledged that proinflammatory stimulation during acute hyperglycemia is able to aggravate inflammatory diseases. However, the mechanisms of proinflammatory effects of glucose are controversially discussed. We investigated leukocyte recruitment after intravenous injection of glucose in different inflammatory models using intravital microscopy. Flow chamber experiments, expression analysis, functional depletion, and knockout of key adhesion molecules gave mechanistic insight in involved pathways. We demonstrated that a single injection of glucose rapidly increased blood glucose levels in a dose-dependent manner. Notably, during tumor necrosis factor (TNF) $\alpha$-induced inflammation leukocyte recruitment was not further enhanced by glucose administration, whereas glucose injection profoundly augmented leukocyte adhesion and transmigration into inflamed tissue in the trauma model, indicating that proinflammatory properties of glucose are stimulus dependent. Experiments with functional or genetic inhibition of the chemokine receptor CXCR2, intercellular adhesion molecule 1 (ICAM1), and lymphocyte function antigen 1 (LFA1) suggest that keratino-derived-chemokine CXCL1-triggered interactions of ICAM1 and LFA1 are crucially involved in the trauma model of inflammation. The lacking effect of glucose on $\beta_{2}$ integrin expression and on leukocyte adhesion in dynamic flow chamber experiments argues against leukocyte-driven underlying mechanisms and favours an endothelial pathway since endothelial ICAM1 expression was significantly upregulated in response to glucose.
\end{abstract}

\section{Introduction}

Although proinflammatory effects of acute hyperglycemia in inflammatory conditions and septic patients have been extensively investigated in clinical as well as experimental settings, there are still controversies about its relevance and mechanisms $[1,2]$. In contrast to earlier studies Brunkhorst et al. found no beneficial effect of treating acute hyperglycemia in the clinical setting of sepsis [3]. However, in this context it was difficult to dissect between effects directly attributable to insulin or thereby induced hypoglycemia. Similarly, hyperglycemia-related proinflammatory effects should be separated into those directly evoked by glucose and those induced by secondary hyperglycemia (stress, inflammation). In case of acute hyperglycemia caused by critical illness, altered secretion of counterregulatory hormones and excessive release of proinflammatory cytokines is observed as well as suppression of the innate immune system $[4,5]$. These consequences of impaired leukocyte function are in part comparable to the pathophysiology observed in patients with diabetes mellitus. Despite tremendous research on proinflammatory conditions related to hyperglycemia direct effects of glucose on leukocyte recruitment during inflammation are poorly studied [6-8].

Leukocyte recruitment into inflamed tissue follows a well-defined cascade of events beginning with the capture of free flowing leukocytes to the vessel wall followed by leukocyte rolling along and adhesion to the inflamed endothelial layer $[9,10]$. During rolling, leukocytes get into intimate contact with the endothelial surface, which allows 
endothelial bound chemokines (i.e., CXCL1) to interact with their specific chemokine receptors (i.e., CXCR2 as the main chemokine receptor on neutrophil leukocytes) on the leukocyte surface. This triggers the activation of $\beta_{2}$-integrins (i.e., LFA1 and MAC1) which leads to firm leukocyte arrest on the endothelium. In addition, integrin-dependent signaling events induce cytoskeletal rearrangements and cell polarization, modifications necessary in helping to prepare the attached leukocyte to spread and crawl in search for its wayout of the vasculature into tissue [10-13]. After crawling along the vessel wall, extravasation takes place as the last distinctive step of the leukocyte recruitment cascade [14].

Little is known about how glucose might interfere with the cascade of leukocyte recruitment in vivo [15]. Acute hyperglycemia severely alters the balance of ana- and catabolic metabolism towards catabolism. Insulin secretion promotes neutrophil chemotaxis under physiological conditions; acute hyperglycemia leads to insulin resistance in and reduced respiratory burst of neutrophil leukocytes [1].

Insulin resistance is seen in different tissues including muscle cells and the substrate producing organ liver. Hepatic insulin resistance leads to an exaggerated release and an increased blood concentration of not only glucose, but also of amino acids and of free fatty acids. Paradoxically, for example, fatty acids are metabolized to a smaller extent in patients with critical illness, leading to a progressively increasing vicious circle of not extractable circulating metabolic substrates [1].

Although experimental design (route and doses of glucose, observed tissue) varied between existing studies, they revealed increased rolling, adhesion and transmigration of leukocytes after glucose application, an effect which was at least in part reversible after insulin injection [7]. Since changes of osmolarity were repeatedly discussed to be causative of alteration of leukocyte recruitment, Azcutia et al. carried out experiments not only with the biological active D-glucose (that is referred to as "glucose" in all existing experimental settings as well as in our investigations), but also with its synthetically existing enantiomer L-glucose [8]. Osmotic changes were not causative in this setting, as Lglucose failed to alter leukocyte recruitment.

Since there are no intravital microscopic studies investigating the immediate effects of glucose on leukocyte recruitment in vivo, we aimed to observe leukocyte recruitment in response to intravenous glucose application in different inflammatory mouse models by intravital microscopy. Based on our experimental results we found that in contrast to $\mathrm{TNF} \alpha$ stimulation leukocyte adhesion and transmigration can be additionally stimulated by glucose, which seems to be dependent on CXCL1-triggered interaction of ICAM1 and LFA1 during trauma-induced inflammation.

\section{Materials and Methods}

$\mathrm{ICAM1}^{-1-}$ mice were generated as described earlier and backcrossed for at least seven generations into the C57bl/6 background [16]. ICAM1 ${ }^{-1-}$ mice were generated by crossbreeding ICAM1 ${ }^{-/-} \mathrm{C} 57 \mathrm{bl} / 6$ mice. $\mathrm{LFA1}^{-/-}$and $\mathrm{C} 57 \mathrm{bl} / 6$ wildtype (WT) mice were provided by Charles River
(Sulzfeld, Germany). All mice were maintained as breeding colonies at the Central Animal Facility of the University of Heidelberg, Germany. For intravital microscopy experiments, mice were at least 8 weeks of age. The animal experiments were approved by the Animal Care and Use Committee of the Regierungspräsidium Karlsruhe, Germany.

In certain experiments, recombinant murine TNF $\alpha$ (R\&D systems, Minneapolis, USA) was injected intrascrotally at a dose of $500 \mathrm{ng}$ per mouse 3 hours before intravital microscopy. In some experiments, recombinant murine chemokine CXCL1 (keratinocyte-derived chemokine KC; Peprotech, London, UK) was injected systemically at a dose of $600 \mathrm{ng}$ per mouse. Blocking antibodies against murine MAC1 (Tib128, clone M1/70, rat IgG2b) and murine LFA1 (Tib217, clone M17/4, rat IgG2a) were obtained from American Type Culture Collection (ATCC, Manasses, USA) and systemically administered with a dose of $100 \mu \mathrm{g}$ per mouse. Bordetella pertussis PTx was purchased from SigmaAldrich (Taufkirchen, Germany) and administered in certain experiments at a dose of $4 \mu \mathrm{g}$ per mouse $3 \mathrm{~h}$ prior to preparation in the trauma model.

2.1. Intravital Microscopy. Mice were prepared for intravital microscopy as reported recently [17]. Briefly, after intraperitoneal (i.p.) injection of ketamine $(125 \mathrm{mg} / \mathrm{kg}$ body weight, Ketalar; Parke-Davis, Morris Plains, USA) and xylazine $(12.5 \mathrm{mg} / \mathrm{kg}$ body weight; Phoenix Scientific, Inc., St. Joseph, USA) mice were placed on a heating pad to maintain body temperature. Intravital microscopy was conducted on an upright microscope (Leica; Wetzlar, Germany) with a saline immersion objective (SW40/0.75 numerical aperture, Zeiss, Jena, Germany). Mice were intubated, and the left carotid artery was cannulated for blood sampling and the right jugular vein for glucose and systemic mAb administration. D-glucose $(200 \mathrm{mg} / \mathrm{mL})$ was administered in doses of $0,25 \mathrm{~g}$, $0,5 \mathrm{~g}$, and $1 \mathrm{~g} / \mathrm{kg}$ body weight. The injection of the equivalent volume of normal saline $(\mathrm{NaCl} 0,9 \%)$ served as control agent. Additional osmotic controls were performed with the biologically inactive L-glucose, purchased from SigmaAldrich (Taufkirchen, Germany). The labeling "glucose" refers to D-glucose that was used in all other experiments that were carried out. This labeling is applied to the entire manuscript. Blood glucose measurements were carried out throughout the experiment using AccuChek (Roche Diagnostics, Mannheim, Germany) and additionally verified by comparing the results in sodium fluoride samples in the Central Laboratory of the University Hospital Heidelberg (Analysezentrum, Heidelberg, Germany).

2.2. Cremaster Muscle Preparation. The surgical preparation of the cremaster muscle was conducted as described previously [17]. Briefly, the scrotum was opened and the cremaster muscle exteriorized. After longitudinal incision and spreading of the muscle over a cover glass, the epididymis and testis were mobilized and pinned aside leading to full microscopic access to the cremaster muscle microcirculation. Cremaster muscle venules were recorded via CCD camera $(\mathrm{CF} 8 / 1$, Kappa, Gleichen, Germany) on a Panasonic S-VHS recorder. The cremaster muscle was superfused with thermocontrolled 
$\left(35^{\circ} \mathrm{C}\right)$ bicarbonate-buffered saline. Postcapillary venules under observation were recorded before and during glucose administration and ranged from 20 to $40 \mu \mathrm{m}$ in diameter. Systemic blood samples $(10 \mu \mathrm{L})$ were taken and assessed for white blood cell count before and after experiment. Systemic blood samples $(10 \mu \mathrm{L})$ were taken after each $\mathrm{mAb}$ injection and stained with Türks solution 1:10 (Merck, Darmstadt, Germany). In some experiments, recombinant murine chemokine KC (keratinocyte-derived chemokine; Peprotech, London, UK) was injected systemically at a dose of $600 \mathrm{ng}$ per mouse. Systemic leukocyte concentration was analyzed using a hematocytometer and expressed as number of leukocytes per $\mu \mathrm{L}$ of whole blood. Microvascular parameters (venular diameter, venular vessel segment length, and leukocyte rolling velocity) were measured using an image-processing system [18]. Venular centerline red blood cell velocity was measured during the experiment via a dual photodiode and a digital online cross-correlation program (Circusoft Instrumentation, Hockessin, USA). An empirical factor of 0.625 was used to convert centerline velocities to mean blood flow velocities [19]. Wall shear rates $\left(\gamma_{w}\right)$ were estimated as $4.9\left(8 v_{b} / d\right)$, where $v_{b}$ is mean blood flow velocity and $d$ the diameter of the vessel $[20,21]$.

2.3. Whole Mount Histology. To differentially count intravascular and extravascular leukocytes, cremaster muscle-whole mounts were prepared as described before [22, 23]. Briefly, while the cremaster muscle was still mounted on the stage for intravital microscopy, the tissue was fixed with $4 \%$ paraformaldehyde in $0.1 \mathrm{M}$ phosphate buffer ( $\mathrm{pH}$ 7.4). The cremaster muscle was removed and mounted flat on a superfrost glass slide (Menzel, Braunschweig, Germany), air dried for 5-10 min, and fixed in 4\% paraformaldehyde in $0.1 \mathrm{M}$ phosphate buffer ( $\mathrm{pH} 7.4$ ) for $24 \mathrm{~h}$ at $4^{\circ} \mathrm{C}$. After fixation, the tissue was washed three times in $0.1 \mathrm{M}$ phosphate buffer with $5 \%$ ethanol, stained with Giemsa (Sigma) at room temperature for $5 \mathrm{~min}$, and differentiated in $0.01 \%$ acetic acid for contrast. The differentiated slides were washed in water, 75\% ethanol, 95\% ethanol, 100\% ethanol, and fresh xylene, followed by mounting in mounting media (AGAR Scientific). The Giemsa-stained cremaster muscles were observed using a Leica DMRB upright microscope and a 25/0,75 NA oil immersion objective (both Leica, Germany). Intravascular and interstitial leukocytes were counted and differentiated into neutrophils, eosinophils, and mononuclear cells.

2.4. Immunohistochemistry. To investigate the endothelial expression of ICAM1 on unstimulated cremaster muscle venules or during trauma-induced inflammation, we performed immunohistochemical analysis of whole-mount cremaster muscles as described $[24,25]$. Briefly, after insertion of a catheter into the carotid artery, primary antibodies against ICAM1 (YN-1, monoclonal rat anti-mouse; $30 \mu \mathrm{g} /$ mouse, ATCC, Wesel, Germany) were systemically injected and incubated for 10 minutes. Because of the intravascular antibody application, which was performed before surgical preparation of the cremaster muscle, binding of antibodies is mostly restricted to surface expressed antigens within the vasculature. For unstimulated venules, excess antibody was washed out from the circulation with normal saline solution before the cremaster muscle was obtained. For trauma-stimulated venules, washing out of excess antibody occurred after exteriorization of the cremaster muscle and 20 minutes of superfusion with superfusion buffer. Cremaster muscle whole mounts were surgically prepared as reported previously [24] and transferred onto adhesive slides (Superfrost, Menzel, Braunschweig, Germany). After air-drying over 5-10 min, cremaster muscles were fixed in acetone $\left(-18^{\circ} \mathrm{C}\right)$ overnight. Permeabilization of the tissue was conducted in $0.05 \mathrm{~mol} / \mathrm{L}$ Tris buffer containing $0.003 \%$ saponine. After washing, cremaster muscle tissue was incubated with biotin-conjugated secondary goat antirat antibody (eBioscience, USA) over $45 \mathrm{~min}$ in a humid chamber. Blocking of endogenous peroxidase activity was performed with $\mathrm{H}_{2} \mathrm{O}_{2}$ in methanol over $1 \mathrm{~h}$, followed by incubation of the tissue with peroxidase-conjugated streptavidin. Staining of tissue samples was performed using a commercially available kit (DAB, Vector Lab, Burlingame, USA). For counter-staining Mayer's hemalaun (Merck, Germany) was applied. Thereafter, the samples were incubated with an increasing concentration of alcohol followed by xylene (Carl Roth, Karlsruhe, Germany). Sealing of tissue samples was performed with mounting medium (DPX Mounting Medium, AGAR Scientific, Stansted Essex, UK).

Analysis of stained slides was conducted on a Leica DMRB upright microscope and a $\times 25 / 0.75$ NA oil immersion objective (both Leica, Wetzlar, Germany). Photographs of the samples were taken using a color CCD camera (KAPPA, Germany).

\subsection{Isolation of Bone Marrow Neutrophils. Murine bone mar-} row PMNs were isolated from femurs and tibias, as described previously [26]. After isolation, they were loaded on top of a discontinuous Percoll gradient (52\%/64\%/72\%) and centrifuged at $1000 \mathrm{~g}$ for 30 minutes. PMNs were harvested from the $64 \% / 72 \%$ interface, washed in PBS, and cultivated for 24 hours in RPMI 1640 medium supplemented with 20\% WEHI-3B-conditioned medium. PMN viability was greater than $95 \%$ as assessed by the trypan blue exclusion test, and purity was greater than $98 \%$ as analyzed by microscopy using Hemacolor staining (Merck, Darmstadt, Germany).

2.6. Flow Cytometry. The expression of MAC1 and LFA1 on bone marrow-derived neutrophils was assessed by flow cytometry. After red blood cell lysis, $10^{6}$ leukocytes $/ \mathrm{mL}$ were stimulated for $15 \mathrm{~min}$ with $10 \mathrm{mg}$ glucose at $37^{\circ} \mathrm{C}$. Next, cells were incubated in the dark with FITC-conjugated antiMAC1 mAb M1/70 ( $1 \mu \mathrm{g} / 10^{5}$ cells, rat IgG2b; eBioscience, San Diego, USA), FITC-conjugated anti-LFA1 mAb M17/4 $\left(1 \mu \mathrm{g} / 10^{5}\right.$ cells, rat IgG2a; eBioscience, San Diego, USA), or respective FITC-conjugated isotype control antibodies $\left(1 \mu \mathrm{g} / 10^{5}\right.$ cells, rat IgG2b or rat IgG2a; eBioscience, San Diego, USA) to detect anti-MAC1 and anti-LFA1 signals, respectively. MAC1 and LFA1 expression was assessed on 10.000 cells per mouse within the neutrophil cluster defined by forward-side scatter analysis using LSRII with DIVA software package (Becton Dickinson, San Jose, USA). Expression 
of MAC1 and LFA1 upon stimulation with different glucose concentrations was compared to unstimulated cells and their respective isotype controls.

2.7. Flow Chamber Assay. Flow chamber experiments were conducted as described $[23,27]$. In brief, rectangular microglass capillaries (VitroCom, Mountain Lakes, USA) were coated with rmP-selectin $(2 \mu \mathrm{g} / \mathrm{mL}), \operatorname{rmCXCL} 1(5 \mu \mathrm{g} / \mathrm{mL})$, and ICAM1 $(1 \mu \mathrm{g} / \mathrm{mL})$ and connected via PE tubing to a $2 \mathrm{~mL}$ syringe containing freshly isolated bone marrow neutrophils from LysEGFP mice. In LysEGFP mice the enhanced GFP (EGFP) is knocked into the murine lysozyme $\mathrm{M}$ (lys) locus leading to the expression of EGFP in myelomonocytic cells. The cell suspension $\left(0.25 \times 10^{6} \mathrm{GFP}\right.$ positive cells $)$ was perfused through the flow chamber and adhesion of GFP-positive cells observed by fluorescence microscopy (BX51 WI with a saline immersion objective $\times 20 / 0.95$ NA, Olympus Hamburg) for 10 minutes under constant flow conditions using a high precision perfusion pump (Harvard Instruments, March-Hugstetten, Germany; wall shear stress $0.1 \mathrm{~Pa})$. Images were recorded via a CCD camera system (CF8HS; Kappa) on a Panasonic S-VHS recorder. In some experiments, cell suspensions were incubated with D-glucose ( $10 \mathrm{mg} / 10^{6}$ cells) 15 minutes before the perfusion through the flow chamber.

2.8. Statistics. Sigma Stat 3.5 (Systat Software, Erkrath, Germany) was used for statistical analysis. Leukocyte counts, vessel diameters, leukocyte adhesion, leukocyte-rolling flux fractions, wall shear rates, and in vitro leukocyte adhesion between groups and treatments were compared with oneway ANOVA followed by a multiple pairwise comparison test (Dunn's test) or by Wilcoxon rank-sum test, as appropriate. Statistical significance was set at $P<0.05$.

\section{Results and Discussion}

3.1. Glucose-Dependent Leukocyte Adhesion and Transmigration in Trauma-Induced Inflammation. The first objective of our experiments was triggering a significant increase of the murine blood glucose concentration by intravenous glucose application. As described earlier, stress (induced by anesthesia and surgical preparation) resulted in high basal blood glucose levels in all investigated mice [28]. As expected one minute after glucose injection blood glucose concentration increased significantly in a dose-dependent manner (See Supplemental Table 1 available online at doi:10.1155/2012/739176). In contrast, recent studies [7, 8] did not detect elevation of systemic blood glucose levels presumably due to different experimental setup (intraperitoneal injection of glucose and longer-time interval until microscopic observation). Because we observed a rapid and significant increase of systemic blood glucose concentration after a dose of $0,5 \mathrm{~g} / \mathrm{kg}$ glucose, which is in the range clinically used to treat severe hypoglycemia [29], we continued with that dose in all further experiments.

Surgical preparation of the cremaster muscle induces leukocyte adhesion mainly via the chemokine CXCL1CXCR2 pathway and $\beta_{2}$ integrins LFA1 and MAC1 in the short-term model of trauma-induced inflammation [23, 27]. Using this model we analyzed the number of adherent leukocytes in WT mice in postcapillary venules of the cremaster muscle before and after intravenous injection of different doses of glucose. The results obtained from these experiments were compared to injection of normal saline and Lglucose. There were no differences in hemodynamic and microvascular parameters (vascular diameter, blood flow velocity, wall shear rate, and white blood cell count) before and after glucose or saline injection (Table 1). Thereby, we ruled out that alterations of leukocyte recruitment might be caused by hemodynamic changes in response to fluid injection.

Administration of a low dose of $0,25 \mathrm{~g} / \mathrm{kg}$ glucose did not lead to any significant changes of leukocyte adhesion. However, increasing doses of glucose $(0,5 \mathrm{~g} / \mathrm{kg}$ and $1 \mathrm{~g} / \mathrm{kg}$, resp.) lead to a significant, dose-dependent increase of leukocyte adhesion in WT mice within 15 minutes after glucose administration (Figure 1(a)) compared to controls injected with normal saline or L-glucose. These results suggest that glucose triggers leukocyte adhesion which is not attributable to hemodynamic changes.

To investigate the impact of glucose on neutrophil transmigration, we also performed Giemsa staining of wholemount cremaster muscles in this model and classified leukocytes into neutrophils, eosinophils, and mononuclear cells as described [17]. Accordingly, the number of perivascular neutrophils was higher after administration of glucose compared to saline controls suggesting that glucose-triggered leukocyte adhesion translates into increased transmigration of leukocytes, too (Figures 1(b)-1(d)). Taken together, leukocyte recruitment during trauma induced inflammation can be rapidly enhanced by intravenous glucose injection. Despite different experimental design, this observation is consistent with intravital microscopic studies on mesenterial vessels of Schäffler et al., Booth et al., and Azcutia et al. [6-8]. Importantly, neither changes of hemodynamic conditions nor osmolarity $[6,8]$ are causative for the observed glucose induced effects. Moreover, there is evidence that glucose triggered leukocyte recruitment is reversible through insulin treatment [7].

\subsection{Glucose-Dependent Leukocyte Adhesion and Transmi-} gration during TNF $\alpha$-Induced Inflammation. As a potent proinflammatory agent, we administered $T N F \alpha$ in a dose of $500 \mathrm{ng} 3 \mathrm{~h}$ prior to exteriorization of the cremaster muscle and observed leukocyte adhesion in cremaster muscle venules of WT mice, either treated with glucose or normal saline. In this model, transition from leukocyte rolling to firm adhesion after TNF $\alpha$ pretreatment is mediated in an overlapping fashion involving CXCR2 and E selectin [30].

Microvascular parameters for the groups are presented in Table 2 and show similar vessel diameters, centerline velocities, wall shear rates, and WBC counts. Administration of $0,5 \mathrm{~g} / \mathrm{kg}$ glucose did not significantly increase leukocyte adhesion in the TNF $\alpha$ model when compared to injection of normal saline (Figure 2(a)).

To investigate whether glucose alters neutrophil transmigration, we performed Giemsa staining of whole mounts 
TABLE 1: Hemodynamic and microvascular parameters of cremaster muscle venules before and after stimulation with glucose in the trauma model. Vessel diameter, centerline velocity, and wall shear rate are displayed before and after the intravenous administration of different doses of glucose and compared to the application of the equivalent volume of normal saline and the biologically inactive L-glucose. Experiments are presented as mean \pm SEM; n.s.: not significant, stating no differences of hemodynamic parameters among the different doses and during the time course after glucose/saline injection.

\begin{tabular}{|c|c|c|c|c|c|c|}
\hline & $\begin{array}{c}\text { Mice } \\
N\end{array}$ & $\begin{array}{c}\text { Venules } \\
n\end{array}$ & $\begin{array}{l}\text { Diameter } \\
(\mu \mathrm{m})\end{array}$ & $\begin{array}{l}\text { Centerline velocity } \\
\qquad(\mu \mathrm{m} / \mathrm{s})\end{array}$ & $\begin{array}{l}\text { Wall shear rate } \\
\qquad\left(\mathrm{s}^{-1}\right)\end{array}$ & $\begin{array}{l}\text { Systemic leukocyte counts } \\
\qquad(/ \mu \mathrm{L})\end{array}$ \\
\hline \multicolumn{7}{|c|}{ Saline injection } \\
\hline Pre-saline & 4 & 18 & $28 \pm 1$ & $2200 \pm 100$ & $1900 \pm 100$ & $6300 \pm 300$ \\
\hline $5^{\prime}$ after saline & 4 & 18 & $28 \pm 1$ & $2300 \pm 100$ & $1900 \pm 100$ & $6200 \pm 200$ \\
\hline \multirow[t]{2}{*}{$15^{\prime}$ after saline } & 4 & 18 & $28 \pm 1$ & $2400 \pm 100$ & $2000 \pm 100$ & $5900 \pm 400$ \\
\hline & & & n.s. & n.s. & n.s. & n.s. \\
\hline \multicolumn{7}{|c|}{ Injection of $0,25 \mathrm{~g} / \mathrm{kg}$ glucose } \\
\hline Pre-glucose & 3 & 12 & $30 \pm 1$ & $2400 \pm 100$ & $2400 \pm 100$ & $4300 \pm 200$ \\
\hline $5^{\prime}$ after glucose & 3 & 12 & $30 \pm 1$ & $2400 \pm 100$ & $2000 \pm 100$ & $4300 \pm 200$ \\
\hline \multirow[t]{2}{*}{$15^{\prime}$ after glucose } & 3 & 12 & $30 \pm 1$ & $2400 \pm 100$ & $2000 \pm 100$ & $4400 \pm 200$ \\
\hline & & & n.s. & n.s. & n.s. & n.s. \\
\hline \multicolumn{7}{|c|}{ Injection of $0,5 \mathrm{~g} / \mathrm{kg} \mathrm{L}$-glucose } \\
\hline Pre-glucose & 5 & 26 & $29 \pm 1$ & $2300 \pm 100$ & $1900 \pm 100$ & $4900 \pm 200$ \\
\hline $5^{\prime}$ after glucose & 5 & 13 & $29 \pm 1$ & $2300 \pm 100$ & $1900 \pm 100$ & $4800 \pm 200$ \\
\hline \multirow[t]{2}{*}{$15^{\prime}$ after glucose } & 5 & 18 & $29 \pm 1$ & $2300 \pm 100$ & $2000 \pm 100$ & $4900 \pm 200$ \\
\hline & & & n.s. & n.s. & n.s. & n.s. \\
\hline \multicolumn{7}{|c|}{ Injection of $0,5 \mathrm{~g} / \mathrm{kg}$ glucose } \\
\hline Pre-glucose & 16 & 64 & $28 \pm 1$ & $2200 \pm 100$ & $1900 \pm 100$ & $6500 \pm 100$ \\
\hline $5^{\prime}$ after glucose & 16 & 64 & $28 \pm 1$ & $2300 \pm 100$ & $2000 \pm 200$ & $6200 \pm 200$ \\
\hline \multirow[t]{2}{*}{$15^{\prime}$ after glucose } & 16 & 64 & $28 \pm 1$ & $2400 \pm 100$ & $2000 \pm 100$ & $6400 \pm 100$ \\
\hline & & & n.s. & n.s. & n.s. & n.s. \\
\hline \multicolumn{7}{|c|}{ Injection of $1 \mathrm{~g} / \mathrm{kg}$ glucose } \\
\hline Pre-glucose & 4 & 10 & $27 \pm 1$ & $2300 \pm 100$ & $2200 \pm 100$ & $6300 \pm 200$ \\
\hline $5^{\prime}$ after glucose & 4 & 10 & $27 \pm 1$ & $2400 \pm 100$ & $2100 \pm 100$ & $6300 \pm 200$ \\
\hline \multirow[t]{2}{*}{$15^{\prime}$ after glucose } & 4 & 10 & $27 \pm 1$ & $2300 \pm 100$ & $2100 \pm 200$ & $6300 \pm 200$ \\
\hline & & & n.s. & n.s. & n.s. & n.s. \\
\hline
\end{tabular}

TABLE 2: Hemodynamic and microvascular parameters of cremaster muscle venules before and after stimulation with glucose in the TNF $\alpha$ model. Vessel diameter, centerline velocity, and wall shear rate are displayed before and after the intravenous administration of $0,5 \mathrm{~g} / \mathrm{kg}$ glucose and compared to the application of the equivalent volume of normal saline. Experiments are presented as mean \pm SEM; n.s.: not significant, stating no differences of hemodynamic parameters during the time course after glucose/saline injection.

\begin{tabular}{|c|c|c|c|c|c|c|}
\hline & $\begin{array}{c}\text { Mice } \\
N\end{array}$ & $\begin{array}{c}\text { Venules } \\
n\end{array}$ & $\begin{array}{l}\text { Diameter } \\
(\mu \mathrm{m})\end{array}$ & $\begin{array}{l}\text { Centerline velocity } \\
\qquad(\mu \mathrm{m} / \mathrm{s})\end{array}$ & $\begin{array}{l}\text { Wall shear rate } \\
\qquad\left(\mathrm{s}^{-1}\right)\end{array}$ & $\begin{array}{l}\text { Systemic leukocyte counts } \\
\qquad(/ \mu \mathrm{L})\end{array}$ \\
\hline \multicolumn{7}{|c|}{ Injection of saline } \\
\hline Pre-saline & 4 & 9 & $28 \pm 1$ & $1900 \pm 100$ & $1800 \pm 200$ & $4200 \pm 200$ \\
\hline $5^{\prime}$ after saline & 4 & 9 & $28 \pm 1$ & $1900 \pm 100$ & $1800 \pm 200$ & $4300 \pm 200$ \\
\hline \multirow[t]{2}{*}{$15^{\prime}$ after saline } & 4 & 9 & $28 \pm 1$ & $1900 \pm 100$ & $1800 \pm 100$ & $4300 \pm 200$ \\
\hline & & & & n.s. & n.s. & n.s. \\
\hline \multicolumn{7}{|c|}{ Injection of glucose } \\
\hline Pre-glucose & 5 & 17 & $27 \pm 1$ & $1900 \pm 100$ & $1800 \pm 100$ & $3700 \pm 200$ \\
\hline $5^{\prime}$ after glucose & 5 & 17 & $27 \pm 1$ & $2200 \pm 100$ & $1900 \pm 100$ & $3700 \pm 200$ \\
\hline \multirow[t]{2}{*}{$15^{\prime}$ after glucose } & 5 & 17 & $27 \pm 1$ & $2000 \pm 100$ & $1800 \pm 100$ & $3900 \pm 200$ \\
\hline & & & & n.s. & n.s. & n.s. \\
\hline
\end{tabular}




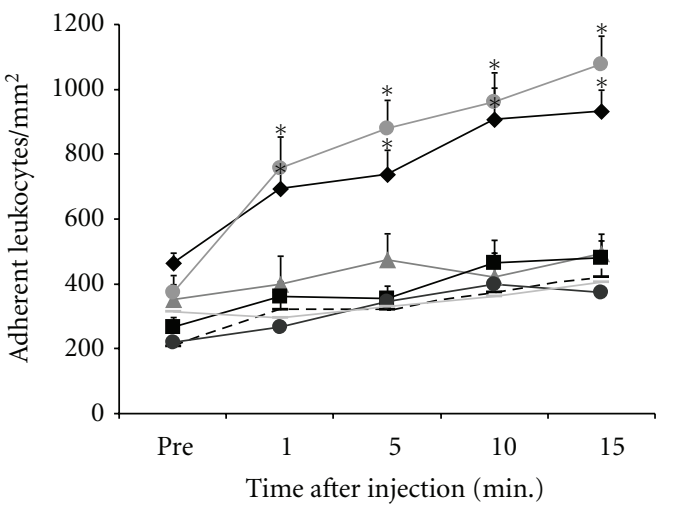

$\multimap 0.5 \mathrm{~g} / \mathrm{kg}$ glucose $\rightarrow$ Saline
$\rightarrow$ WT PTX glucose --- WT ICAM1-KO glucose
$\rightarrow$ LFA1-KO glucose $\rightarrow-$ WT KC glucose
- WT L-glucose

(a)

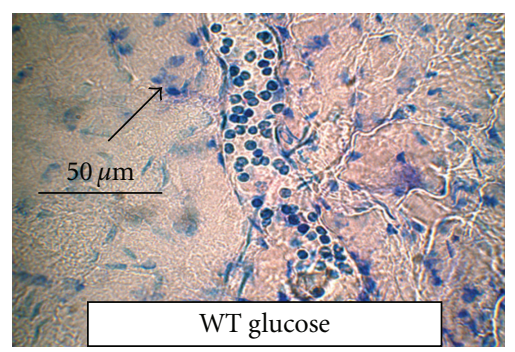

(c)

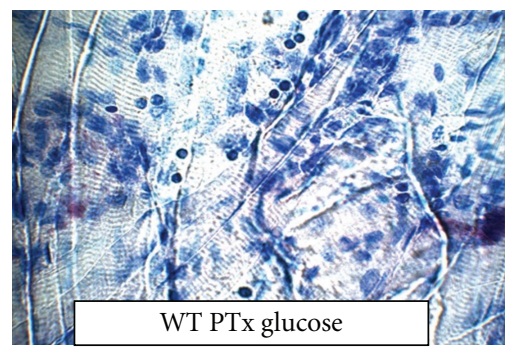

(f)

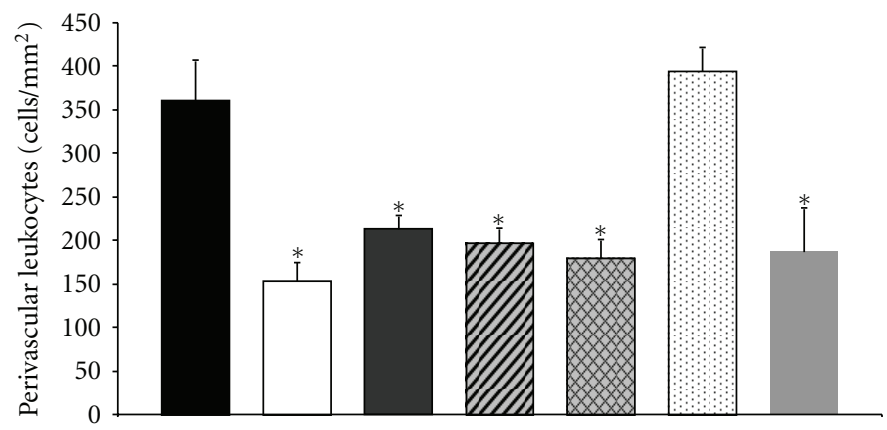
- WT glucose
$\square$ WT PTX glucose
$\square$ LFA1-KO glucose
$\square$ WT saline
$\square$ ICAM1-KO glucose
$\square$ WT KC glucose

- WT L-glucose

(b)

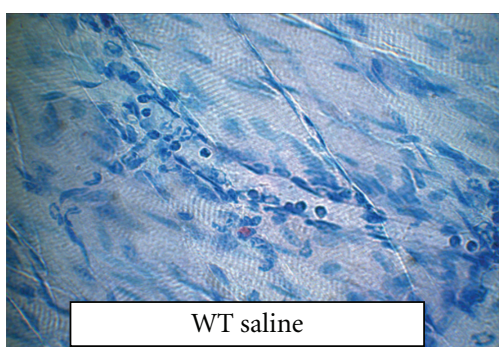

(d)

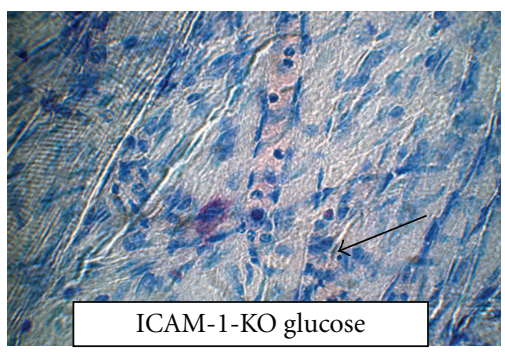

(g)

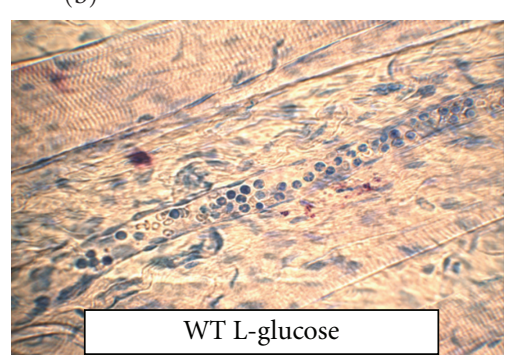

(e)

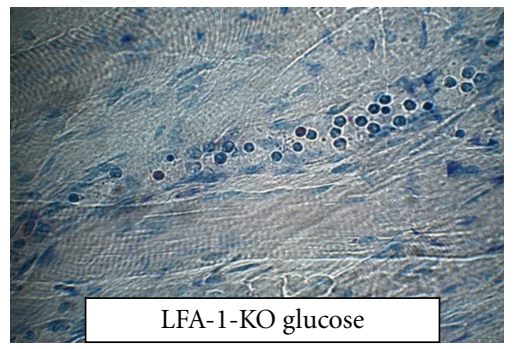

(h)

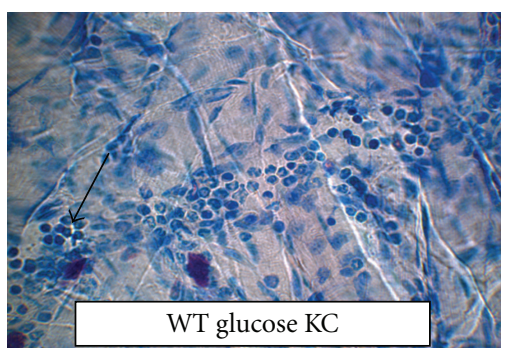

(i)

FIgURE 1: Leukocyte adhesion (number of adherent cells $/ \mathrm{mm}^{2}$ ) in mouse cremaster muscle venules and leukocyte transmigration (perivascular neutrophils $/ \mathrm{mm}^{2}$ surface area) in cremaster muscle whole mounts in response to glucose during trauma-induced inflammation. (a) Leukocyte adhesion was observed in trauma-stimulated cremaster muscle venules of wild-type mice (64 venules in 16 mice), LFA1-KO mice (19-25 venules in 4 mice), and ICAM1-KO mice (18-22 venules in 4 mice) before and during 15 minutes after intravenous injection of $0.5 \mathrm{~g} / \mathrm{kg}$ glucose. To dissect the role of the chemokine pathway in this model, WT mice were either pretreated with $4 \mu \mathrm{g}$ PTx $3 \mathrm{~h}$ prior to cremaster exteriorization and glucose stimulation or coinjected with $600 \mathrm{ng}$ CXCL1 (KC) and glucose and compared to injection of normal saline. WT mice injected with the equivalent volume of normal saline (18 venules in 4 mice) and the biologically inactive L-glucose (13-28 venules in 5 mice) served as controls. (b) Giemsa-stained cremaster muscle whole mounts of WT mice were analyzed for the number of perivascular neutrophils (per $\mathrm{mm}^{2}$ surface area) after injection of glucose or normal saline in the trauma model). In parallel, leukocyte extravasation was quantified in glucose-treated LFA1-KO, ICAM1-KO mice, and WT mice pretreated with $4 \mu \mathrm{g}$ PTx $3 \mathrm{~h}$ prior to cremaster muscle exteriorization or coinjected with $600 \mathrm{ng}$ CXCL1. To further illustrate the results representative micrographs of cremaster muscle whole mounts are shown in (c)-(i). Reference bar is shown in (c). Arrows point to extravasated leukocytes. All values are presented as mean \pm SEM. Significances are indicated by the asterisks $\left({ }^{*} P<0.05\right.$ versus WT control mice). 


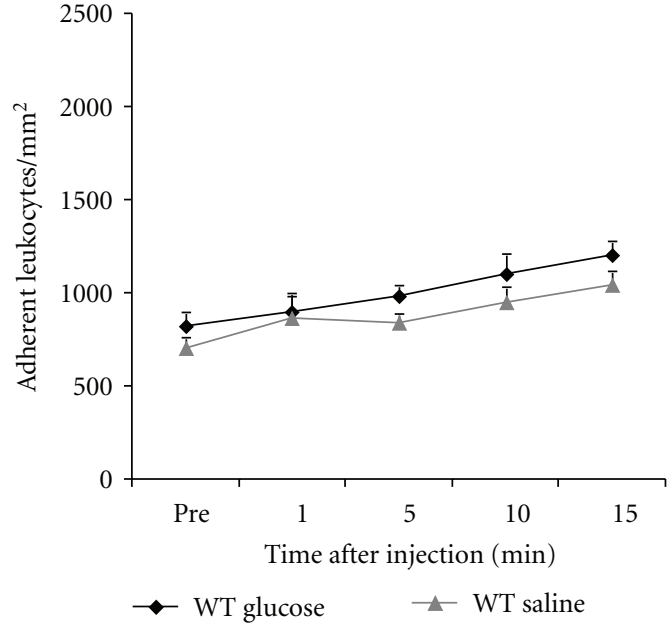

(a)

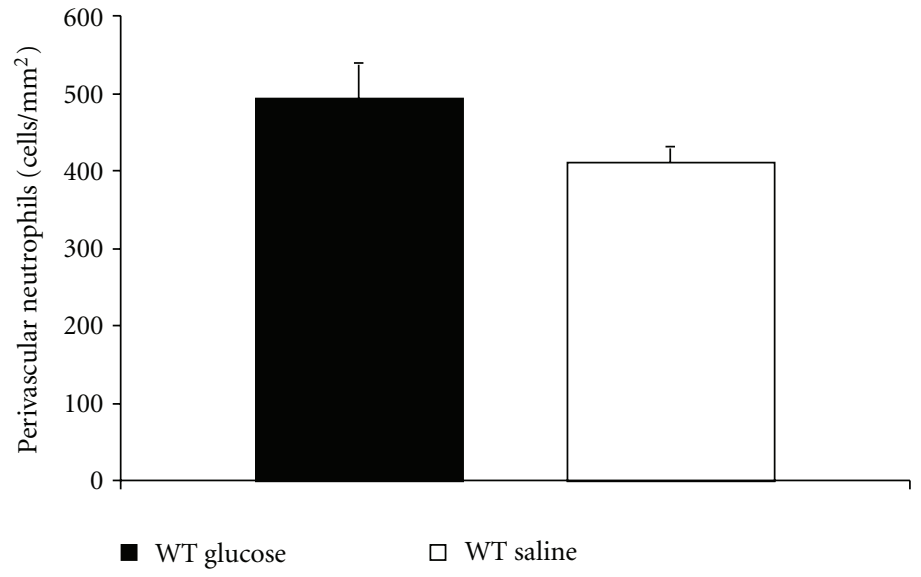

(b)

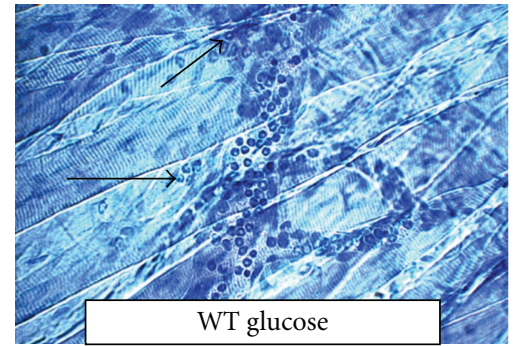

(c)

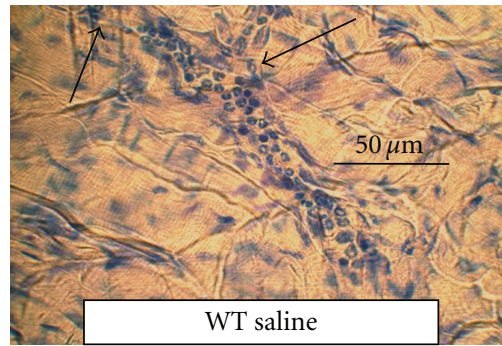

(d)

Figure 2: Leukocyte adhesion (number of adherent cells $/ \mathrm{mm}^{2}$ ) in mouse cremaster muscle venules and leukocyte transmigration (perivascular neutrophils $/ \mathrm{mm}^{2}$ surface area) in cremaster muscle whole mounts in response to glucose during TNF $\alpha$-induced inflammation. (a) Leukocyte adhesion was observed in TNF $\alpha$-stimulated cremaster muscle venules of wild-type mice (17 venules in 5 mice) before and during 15 minutes after intravenous injection of $0.5 \mathrm{~g} / \mathrm{kg}$ glucose and compared to injection of normal saline ( 9 venules in 4 mice). (b) Giemsa-stained whole mounts of TNF $\alpha$-treated cremaster muscles of WT mice were analyzed for the number of perivascular neutrophils after injection of glucose or normal saline. Representative micrographs are depicted in Figures 2(c) and 2(d). Reference bar is presented in Figure 2(d). Arrows point to extravasated leukocytes. All values are presented as mean \pm SEM. Significances are indicated by the asterisks $\left({ }^{*} P<0.05\right.$ versus WT control mice).

of TNF $\alpha$-treated cremaster muscles and classified leukocytes into neutrophils, eosinophils, and mononuclear cells as described [17]. In mice injected with glucose, the number of extravasated neutrophils was hardly increased compared to normal saline-treated mice, indicating that proinflammatory stimulation with $\mathrm{TNF} \alpha$ is not further enhanced by glucose (Figures 2(b)-2(d)).

Thus, glucose exerts proinflammatory effects with regard to leukocyte recruitment in the short-term trauma model, but not in the long-term $\mathrm{TNF} \alpha$ model.

We hypothesize that in contrast to the short term model of trauma-induced inflammation $\mathrm{TNF} \alpha$ induces a very strong $\mathrm{NF} \kappa \mathrm{B}$-triggered proinflammatory stimulation over $3 \mathrm{~h}$ that is not further augmentable by glucose administration. This theory is supported by the fact that the level of leukocyte adhesion and transmigration is about the same after TNF $\alpha$ stimulation compared to trauma-induced inflammation plus glucose.
3.3. Role of ICAM1 and LFA1 for Glucose-Stimulated Leukocyte Adhesion and Transmigration during Trauma-Induced Inflammation. Using ICAM1-KO and LFA1-KO mice we addressed the question whether ICAM1 and LFA1 play a role for the observed glucose-induced effects during leukocyte recruitment during trauma-induced inflammation (hemodynamic and microvascular parameters are presented in Table 3). In line with previous reports $[31,32]$ we found comparable baseline leukocyte adhesion in cremaster muscle venules of WT, LFA1-KO, and ICAM1-KO mice. In contrast to WT mice, injection of $0.5 \mathrm{~g} / \mathrm{kg}$ glucose in $\mathrm{ICAM}^{-/-}$and in $\mathrm{LFA} 1^{-/-}$mice did not lead to significant changes of adherent leukocytes compared to baseline values (Figure 1(a)). Accordingly, transmigration of neutrophils as observed in giemsa-stained cremaster muscle whole mounts of ICAM1$\mathrm{KO}$ and in LFA1-KO mice was similar after administration of glucose compared to normal saline (Figures 1(b), 1(f), and $1(\mathrm{~g}))$. These findings suggest that ICAM1 and LFA1 are crucially involved in mediating glucose-induced leukocyte 


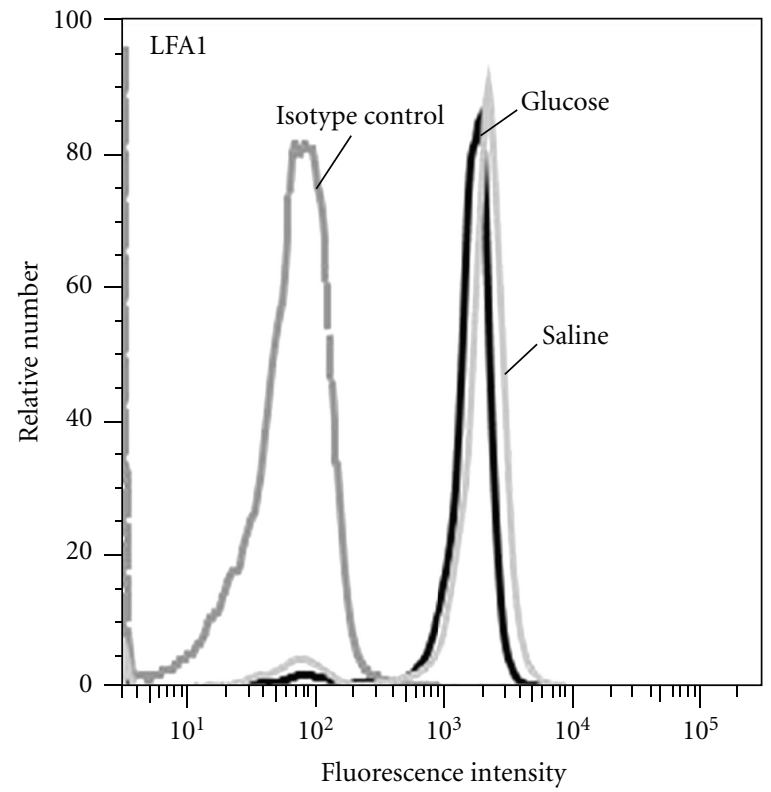

(a)

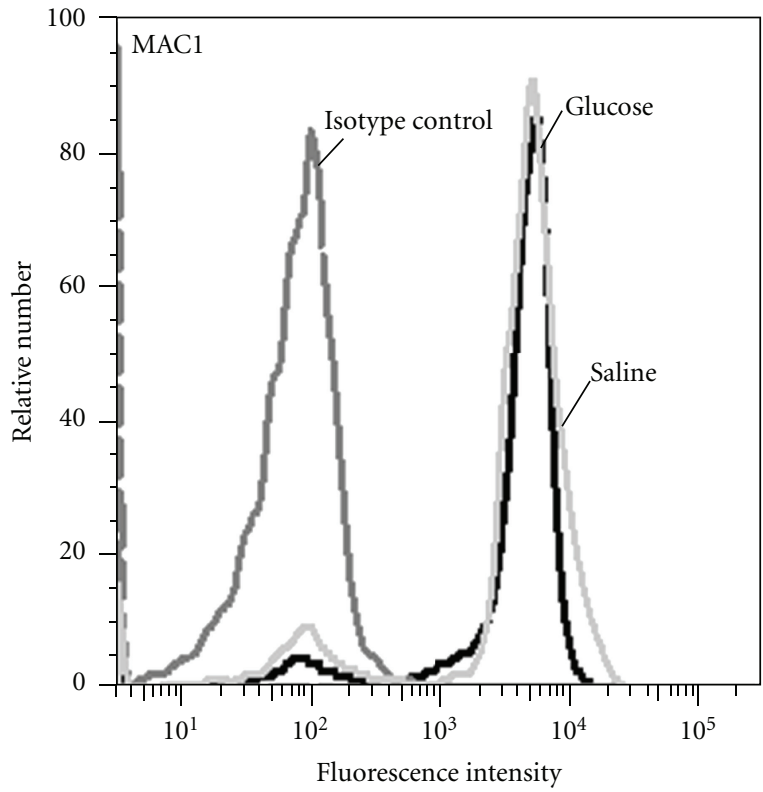

(b)

FIGURE 3: Glucose-dependent expression of LFA1 and MAC1 on neutrophils. Surface expression of LFA1 (a) and MAC1 (b) on bone marrowderived neutrophils $\left(n=3\right.$ mice) after stimulation with glucose $\left(10 \mathrm{mg}\right.$ per $10^{6}$ leukocytes $/ \mathrm{mL}, 1 \mathrm{~h}$ at $\left.37^{\circ} \mathrm{C}\right)$ was compared to unstimulated controls (b). Representative histograms are shown from 3 separate experiments.

recruitment, which is in line with previous observations $[8,33]$.

\subsection{Role of Chemokine CXCL1-CXCR2 Pathway for Glucose-} Stimulated Leukocyte Adhesion and Transmigration during Trauma-Induced Inflammation. In order to gain further insight into underlying mechanisms, we next investigated the role of the CXCL1-CXCR2 pathway for glucose-triggered leukocyte recruitment in our experimental setting. We and others demonstrated that injection of CXCR2-binding chemokine CXCL1 induces a significant increase of leukocyte adhesion which is mostly attributed to LFA1 activation and its subsequent ICAM1 binding [23, 31].

We first asked whether systemically injection of $600 \mathrm{ng}$ CXCL1 in addition to $0.5 \mathrm{~g} / \mathrm{kg}$ glucose would be able to further enhance leukocyte adhesion and transmigration during trauma-induced inflammation (hemodynamic and microvascular parameters are presented in Table 3). However, the number of adherent and transmigrated cells was not further increased in glucose-injected mice after costimulation with CXCL1 compared to glucose injection only (Figures 1(a), 1(b), and 1(h)), indicating that CXCL1 might be involved in glucose-mediated leukocyte recruitment. Next, we used Pertussis toxin (PTx) to unspecifically block the chemokine receptor CXCR2 by disruption of G-proteincoupled receptor signaling [23]. Notably, PTx pretreatment completely abolished leukocyte adhesion or transmigration in response to glucose in our experimental model (Figures 1(a), 1(b), and 1(e)) suggesting that the CXCL1CXCR2 pathway is involved in mediating glucose-induced leukocyte recruitment.
3.5. Glucose-Dependent Expression of LFA1 and MAC1 on Bone Marrow-Derived Neutrophils. To further explore underlying mechanisms for the observed glucose-induced effects we analyzed the expression of the $\beta_{2}$ integrins LFA1 and MAC1 on neutrophils in response to glucose using flow cytometry. As depicted in Figure 3, expression of LFA1 and MAC1 on bone marrow-derived mouse neutrophils was not altered after incubation with $10 \mathrm{mg} / \mathrm{mL}$ glucose for 15 minutes when compared to control neutrophils. This finding indicates that upregulation of $\beta_{2}$ integrins does not account for the observed glucose-induced augmentation of leukocyte recruitment. Therefore, the changes of leukocyte recruitment are unlikely to be attributable to leukocyte-driven mechanism, as signaling of glucose-incubated leukocytes is identical to leukocytes incubated with saline. Glucose-evoked changes of integrin avidity or activity are difficult to exclude in our flow cytometric approach, as respective antibodies are not available in mice.

3.6. Leukocyte Adhesion during Dynamic Microflow Chamber Experiments. Next, we aimed to further dissect leukocytefrom endothelium-driven mechanisms mediating glucoseinduced adhesion of leukocytes and performed flow chamber experiments. Therefore, microflow chambers were coated with P selectin, ICAM1, and KC and constantly perfused with isolated glucose-stimulated or saline control bone marrow neutrophils of $L y s E G F P$ mice. Under control conditions we observed a significant number of adherent GFP-positive cells (mainly neutrophils) in fully coated flow chamber compared to uncoated flow chambers (Figure 4). Noteworthy, glucose stimulation $(10 \mathrm{mg} / \mathrm{mL}$ for 15 minutes $)$ did not affect 
TABLE 3: Hemodynamic and microvascular parameters of cremaster muscle venules in ICAM1-KO, LFA1-KO, and PTx-pretreated or KCcoinjected WT mice before and after injection $0,5 \mathrm{~g} / \mathrm{kg}$ glucose in the trauma model. Vessel diameter, centerline velocity, and wall shear rate are displayed before and after the intravenous administration of glucose. Experiments are presented as mean \pm SEM; n.s.: not significant stating no differences of hemodynamic parameters among the different groups and during the time course after glucose/saline injection.

\begin{tabular}{|c|c|c|c|c|c|c|}
\hline & $\begin{array}{c}\text { Mice } \\
N\end{array}$ & $\begin{array}{c}\text { Venules } \\
n\end{array}$ & $\begin{array}{c}\text { Diameter } \\
(\mu \mathrm{m})\end{array}$ & $\begin{array}{l}\text { Centerline velocity } \\
\qquad(\mu \mathrm{m} / \mathrm{s})\end{array}$ & $\begin{array}{l}\text { Wall shear rate } \\
\qquad\left(\mathrm{s}^{-1}\right)\end{array}$ & $\begin{array}{l}\text { Systemic leukocyte counts } \\
\qquad(/ \mu \mathrm{L})\end{array}$ \\
\hline \multicolumn{7}{|c|}{ WT mice } \\
\hline Pre-glucose & 16 & 64 & $28 \pm 1$ & $2200 \pm 100$ & $1900 \pm 100$ & $6500 \pm 100$ \\
\hline $5^{\prime}$ after glucose & 16 & 64 & $28 \pm 1$ & $2300 \pm 100$ & $2000 \pm 200$ & $6200 \pm 200$ \\
\hline \multirow[t]{2}{*}{$15^{\prime}$ after glucose } & 16 & 64 & $28 \pm 1$ & $2400 \pm 100$ & $2000 \pm 100$ & $6400 \pm 100$ \\
\hline & & & n.s. & n.s. & n.s. & n.s. \\
\hline \multicolumn{7}{|c|}{ Coinjection with KC in WT mice } \\
\hline Pre-glucose & 4 & 16 & $27 \pm 1$ & $2200 \pm 100$ & $2200 \pm 100$ & $5900 \pm 300$ \\
\hline $5^{\prime}$ after glucose & 4 & 12 & $27 \pm 1$ & $2300 \pm 100$ & $2200 \pm 100$ & $6000 \pm 200$ \\
\hline \multirow[t]{2}{*}{$15^{\prime}$ after glucose } & 4 & 14 & $27 \pm 1$ & $2200 \pm 100$ & $2000 \pm 100$ & $6000 \pm 200$ \\
\hline & & & n.s. & n.s. & n.s. & n.s. \\
\hline \multicolumn{7}{|c|}{ PTx-pretreatment in WT mice } \\
\hline Pre-glucose & 4 & 16 & $29 \pm 1$ & $2200 \pm 100$ & $2000 \pm 100$ & $5700 \pm 300$ \\
\hline $5^{\prime}$ after glucose & 4 & 15 & $29 \pm 1$ & $2300 \pm 200$ & $2000 \pm 200$ & $5200 \pm 500$ \\
\hline \multirow[t]{2}{*}{$15^{\prime}$ after glucose } & 4 & 16 & $29 \pm 1$ & $2400 \pm 100$ & $2000 \pm 100$ & $5300 \pm 300$ \\
\hline & & & n.s. & n.s. & n.s. & n.s. \\
\hline \multicolumn{7}{|c|}{ LFA1-KO mice } \\
\hline Pre-glucose & 4 & 25 & $28 \pm 1$ & $2500 \pm 100$ & $2200 \pm 100$ & $7600 \pm 500$ \\
\hline $5^{\prime}$ after glucose & 4 & 19 & $28 \pm 1$ & $2400 \pm 100$ & $2200 \pm 100$ & $8000 \pm 300$ \\
\hline \multirow[t]{2}{*}{$15^{\prime}$ after glucose } & 4 & 20 & $28 \pm 1$ & $2500 \pm 100$ & $2200 \pm 100$ & $8100 \pm 300$ \\
\hline & & & n.s. & n.s. & n.s. & n.s. \\
\hline \multicolumn{7}{|c|}{$\mathrm{ICAM}^{-/-}$mice } \\
\hline Pre-glucose & 4 & 22 & $27 \pm 1$ & $2300 \pm 100$ & $2300 \pm 100$ & $6000 \pm 400$ \\
\hline $5^{\prime}$ after glucose & 4 & 18 & $27 \pm 1$ & $2500 \pm 100$ & $1800 \pm 100$ & $6200 \pm 500$ \\
\hline \multirow[t]{2}{*}{$15^{\prime}$ after glucose } & 4 & 21 & $27 \pm 1$ & $2400 \pm 100$ & $2300 \pm 100$ & $6100 \pm 400$ \\
\hline & & & n.s. & n.s. & n.s. & n.s. \\
\hline
\end{tabular}

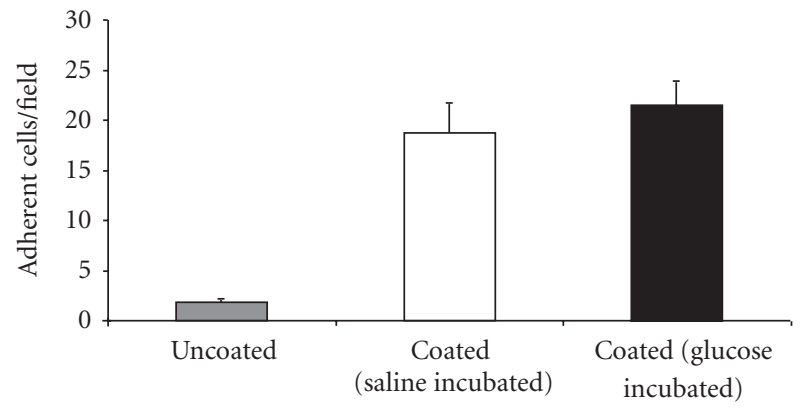

Figure 4: Comparison of adherent cells in microflow chambers perfused with glucose or saline. Microflow chambers were coated with $\mathrm{P}$ selectin, ICAM1, and $\mathrm{KC}$ and constantly perfused with isolated glucose-stimulated or saline control bone marrow neutrophils of LysEGFP mice $(n=4)$. Adhesion of leukocytes in fully coated flow chambers was compared to uncoated flow chambers.

leukocyte adhesion in this dynamic flow chamber approach, indicating that leukocyte-born mechanisms are unlikely to be connected to glucose-induced changes of leukocyte recruitment.
3.7. Glucose-Dependent ICAM1 Expression in Surgically Prepared Cremaster Muscle Venules. We next ask about the impact of glucose on the regulation of endothelial adhesion molecules. Since interaction of LFA1 with ICAM1 is involved in mediation of glucose-induced effects of leukocyte recruitment, we assessed endothelial ICAM1 expression in postcapillary venules of trauma-stimulated cremaster muscles using immunohistochemistry.

Endothelial ICAM1 expression in cremaster muscle venules of glucose treated mice was significantly increased compared to control mice (Figure 5, also illustrated by micrographs). These findings confirm previous observations of Azcutia et al. and others [8,33], strongly suggesting that glucose-dependent enhancement of leukocyte recruitment is at least in part entailed to ICAM1 upregulation. However, future studies are necessary to investigate whether glucose regulates other endothelial leukocyte adhesion molecules acting in concert with ICAM1. In addition, humoral factors cytokines and chemokines could be involved in the glucoseinduced proinflammatory responses, as described by Azcutia et al. and Ling et al. [8, 34].

Based on our presented results we hypothesize that glucose induces CXCL1-CXCR2-dependent activation of 


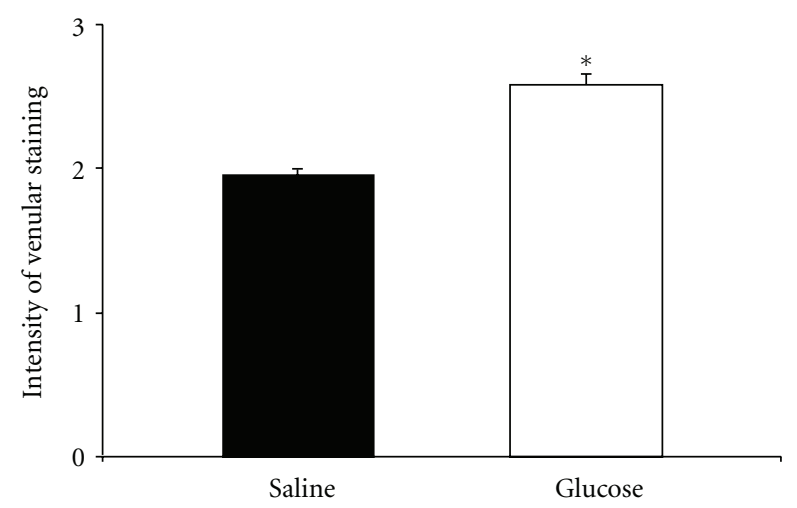

(a)

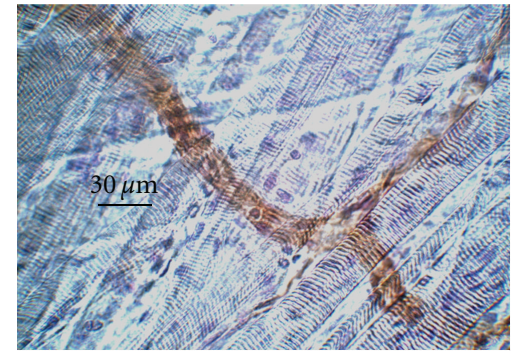

(b)

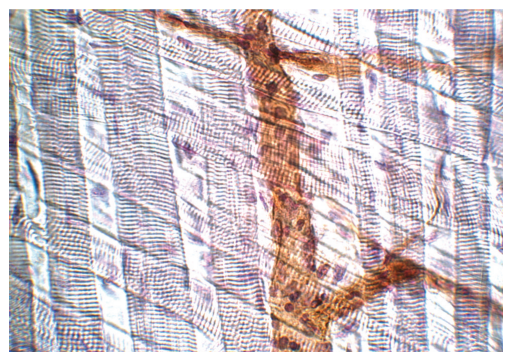

(c)

FIGURE 5: Glucose-induced expression of ICAM1 in surgically prepared cremaster muscle venules. Immunostaining was conducted to assess endothelial expression of ICAM1 in postcapillary venules of cremaster muscles obtained 15 minutes after exteriorization and injection of $0.5 \mathrm{~g} / \mathrm{kg}$ glucose or the equivalent volume of normal saline. Application of primary antibody was performed i.v. before harvesting the cremaster muscle in order to stain ICAM1 on the endothelial surface. Biotinylated secondary antibody, peroxidase-conjugated streptavidin, and diaminobenzidine (DAB) were used to detect endothelial expression of ICAM1 as brown signal. Counter-staining was performed by Mayer's hemalaun. Intensity of venular anti-ICAM1 immunostaining during trauma-induced inflammation was analyzed semiquantitatively and presented as mean \pm SEM (a; $0=$ no, $1=$ weak, $2=$ medium, $3=$ strong signal; at least 3 mice/group). In addition, representative images of saline- and glucose-treated mice are depicted in (b) and (c), respectively. Reference bar is shown in (b) and represents $30 \mu \mathrm{m}$. Significant differences $(P<0.05)$ are indicated by the asterisk.

LFA1 which in turn binds to upregulated ICAM1 in order to mediate leukocyte recruitment. However, up to date it remains unclear whether and how glucose-dependent signaling, that is, glucose receptors or channels are involved in upstream signalling pathways.

To our knowledge, this is the first study that investigated the immediate effects of intravenously administered glucose on the leukocyte recruitment cascade in vivo, so that our results may stimulate future studies further investigating underlying mechanisms of the observed glucose-dependent proinflammatory signaling.

\section{Conclusion}

Leukocyte adhesion and transmigration are strongly augmented by intravenous glucose injection during traumainduced inflammation but not during $3 \mathrm{~h}-\mathrm{TNF} \alpha$ stimulation. The glucose-induced leukocyte recruitment is mediated by CXCL1-triggered interaction of LFA1 and ICAM1. Thus, our results also indicate that the proinflammatory properties of glucose are stimulus-dependent and might open new perspectives for the development of strategies targeting hyperglycemia-related inflammatory conditions.

\section{Authors' Contribution}

K. Buschmann and L. Koch equally contributed to this paper.

\section{Conflict of Interests}

The authors declare that there is no conflict of interests for any of the authors.

\section{Acknowledgments}

The authors thank Melitta Weissinger for her excellent technical assistance in performing intravital microscopy and immunohistochemistry. They also thank Angelika Bierhaus and Eduard Ryschich for providing ICAM1 ${ }^{-/-}$and $\mathrm{LFA}^{-/-}$ mice.

\section{References}

[1] S. K. Andersen, J. Gjedsted, C. Christiansen, and E. Tønnesen, "The roles of insulin and hyperglycemia in sepsis pathogenesis," Journal of Leukocyte Biology, vol. 75, no. 3, pp. 413-421, 2004. 
[2] S. J. Van Cromphaut, I. Vanhorebeek, and G. Van den Berghe, "Glucose metabolism and insulin resistance in sepsis," Current Pharmaceutical Design, vol. 14, no. 19, pp. 1887-1899, 2008.

[3] F. M. Brunkhorst, C. Engel, F. Bloos et al., "Intensive insulin therapy and pentastarch resuscitation in severe sepsis," The New England Journal of Medicine, vol. 358, no. 2, pp. 125-139, 2008.

[4] M. E. Stegenga, S. N. Van Der Crabben, R. M. E. Blümer et al., "Hyperglycemia enhances coagulation and reduces neutrophil degranulation, whereas hyperinsulinemia inhibits fibrinolysis during human endotoxemia," Blood, vol. 112, no. 1, pp. 82-89, 2008.

[5] W. K. Yu, W. Q. Li, N. Li, and J. S. Li, "Influence of acute hyperglycemia in human sepsis on inflammatory cytokine and counterregulatory counterregulatory hormone concentrations," World Journal of Gastroenterology, vol. 9, no. 8, pp. 1824-1827, 2003.

[6] A. Schäffler, H. Arndt, J. Schölmerich, and K. D. Palitzsch, "Acute hyperglycaemia causes severe disturbances of mesenteric microcirculation in an in vivo rat model," European Journal of Clinical Investigation, vol. 28, no. 11, pp. 886-893, 1998.

[7] G. Booth, T. J. Stalker, A. M. Lefer, and R. Scalia, "Elevated ambient glucose induces acute inflammatory events in the microvasculature: effects of insulin," American Journal of Physiology, vol. 280, no. 6, pp. E848-E856, 2001.

[8] V. Azcutia, M. Abu-Taha, T. Romacho et al., "Inflammation determines the pro-adhesive properties of high extracellular D-glucose in human endothelial cells in vitro and rat microvessels in vivo," PLoS ONE, vol. 5, no. 4, Article ID e10091, 2010.

[9] T. A. Springer, "Traffic signals on endothelium for lymphocyte recirculation and leukocyte emigration," Annual Review of Physiology, vol. 57, pp. 827-872, 1995.

[10] K. Ley, C. Laudanna, M. I. Cybulsky, and S. Nourshargh, "Getting to the site of inflammation: the leukocyte adhesion cascade updated," Nature Reviews Immunology, vol. 7, no. 9, pp. 678-689, 2007.

[11] J. Schymeinsky, A. Mócsai, and B. Walzog, "Neutrophil activation via $\beta 2$ integrins (CD11/CD18): molecular mechanisms and clinical implications," Thrombosis and Haemostasis, vol. 98, no. 2, pp. 262-273, 2007.

[12] M. Phillipson, B. Heit, P. Colarusso, L. Liu, C. M. Ballantyne, and P. Kubes, "Intraluminal crawling of neutrophils to emigration sites: a molecularly distinct process from adhesion in the recruitment cascade," Journal of Experimental Medicine, vol. 203, no. 12, pp. 2569-2575, 2006.

[13] C. Laudanna and R. Alon, "Right on the spot. Chemokine triggering of integrin-mediated arrest of rolling leukocytes," Thrombosis and Haemostasis, vol. 95, no. 1, pp. 5-11, 2006.

[14] S. K. Shaw, S. Ma, M. B. Kim et al., "Coordinated redistribution of leukocyte LFA-1 and endothelial cell ICAM-1 accompany neutrophil transmigration," Journal of Experimental Medicine, vol. 200, no. 12, pp. 1571-1580, 2004.

[15] L. M. McManus, R. C. Bloodworth, T. J. Prihoda, J. L. Blodgett, and R. N. Pinckard, "Agonist-dependent failure of neutrophil function in diabetes correlates with extent of hyperglycemia," Journal of Leukocyte Biology, vol. 70, no. 3, pp. 395-404, 2001.

[16] H. Xu, J. A. Gonzalo, Y. S. Pierre et al., "Leukocytosis and resistance to septic shock in intercellular adhesion molecule 1-deficient mice," Journal of Experimental Medicine, vol. 180, no. 1, pp. 95-109, 1994.
[17] M. Sperandio, A. Thatte, D. Foy, L. G. Ellies, J. D. Marth, and K. Ley, "Severe impairment of leukocyte rolling in venules of core 2 glucosaminyltransferase-deficient mice," Blood, vol. 97, no. 12, pp. 3812-3819, 2001.

[18] H. Zeintl, F. U. Sack, M. Intaglietta, and K. Messmer, "Computer assisted leukocyte adhesion measurement in intravital microscopy," International Journal of Microcirculation, vol. 8, no. 3, pp. 293-302, 1989.

[19] H. H. Lipowsky and B. W. Zweifach, "Application of the 'twoslit' photometric technique to the measurement of microvascular volumetric flow rates," Microvascular Research, vol. 15, no. 1, pp. 93-101, 1978.

[20] D. S. Long, M. L. Smith, A. R. Pries, K. Ley, and E. R. Damiano, "Microviscometry reveals reduced blood viscosity and altered shear rate and shear stress profiles in microvessels after hemodilution," Proceedings of the National Academy of Sciences of the United States of America, vol. 101, no. 27, pp. 1006010065, 2004.

[21] M. L. Smith, D. S. Long, E. R. Damiano, and K. Ley, "Near-wall $\mu$-PIV reveals a hydrodynamically relevant endothelial surface layer in venules in vivo," Biophysical Journal, vol. 85, no. 1, pp. 637-645, 2003.

[22] S. B. Forlow and K. Ley, "Selectin-independent leukocyte rolling and adhesion in mice deficient in E-, P-, and L-selectin and ICAM-1," American Journal of Physiology, vol. 280, no. 2, pp. H634-H641, 2001.

[23] D. Frommhold, A. Ludwig, M. G. Bixel et al., "Sialyltransferase ST3Gal-IV controls CXCR2-mediated firm leukocyte arrest during inflammation," Journal of Experimental Medicine, vol. 205, no. 6, pp. 1435-1446, 2008.

[24] U. Jung and K. Ley, "Regulation of E-selectin, P-selectin, and intercellular adhesion molecule 1 expression in mouse cremaster muscle vasculature," Microcirculation, vol. 4, no. 2, pp. 311-319, 1997.

[25] D. Frommhold, J. Tschada, N. Braach et al., "Protein C concentrate controls leukocyte recruitment during inflammation and improves survival during endotoxemia after efficient in vivo activation," American Journal of Pathology, vol. 179, no. 5, pp. 2637-2650, 2011.

[26] J. Schymeinsky, A. Sindrilaru, D. Frommhold et al., "The Vav binding site of the non-receptor tyrosine kinase Syk at Tyr 348 is critical for $\beta_{2}$ integrin (CD11/CD18)-mediated neutrophil migration," Blood, vol. 108, no. 12, pp. 3919-3927, 2006.

[27] M. L. Smith, M. Sperandio, E. V. Galkina, and K. Ley, "Autoperfused mouse flow chamber reveals synergistic neutrophil accumulation through P-selectin and E-selectin," Journal of Leukocyte Biology, vol. 76, no. 5, pp. 985-993, 2004.

[28] K. Susztak, A. C. Raff, M. Schiffer, and E. P. Böttinger, "Glucose-induced reactive oxygen species cause apoptosis of podocytes and podocyte depletion at the onset of diabetic nephropathy," Diabetes, vol. 55, no. 1, pp. 225-233, 2006.

[29] A. Collier, D. J. Steedman, A. W. Patrick et al., "Comparison of intravenous glucagon and dextrose in treatment of severe hypoglycemia in an accident and emergency department," Diabetes Care, vol. 10, no. 6, pp. 712-715, 1987.

[30] M. L. Smith, T. S. Olson, and K. Ley, "CXCR2- and E-selectininduced neutrophil arrest during inflammation in vivo," Journal of Experimental Medicine, vol. 200, no. 7, pp. 935-939, 2004.

[31] D. Frommhold, A. Kamphues, S. Dannenberg et al., "RAGE and ICAM-1 differentially control leukocyte recruitment during acute inflammation in a stimulus-dependent manner," BMC Immunology, vol. 12, article 56, 2011. 
[32] D. Frommhold, A. Kamphues, I. Hepper et al., "RAGE and ICAM-1 cooperate in mediating leukocyte recruitment during acute inflammation in vivo," Blood, vol. 116, no. 5, pp. 841$849,2010$.

[33] A. R. Smolock, G. Mishra, K. Eguchi, S. Eguchi, and R. Scalia, "Protein kinase C upregulates intercellular adhesion molecule1 and leukocyte-endothelium interactions in hyperglycemia via activation of endothelial expressed calpain," Arteriosclerosis, Thrombosis, and Vascular Biology, vol. 31, no. 2, pp. 289296, 2011.

[34] P. R. Ling, R. J. Smith, and B. R. Bistrian, "Hyperglycemia enhances the cytokine production and oxidative responses to a low but not high dose of endotoxin in rats," Critical Care Medicine, vol. 33, no. 5, pp. 1084-1089, 2005. 


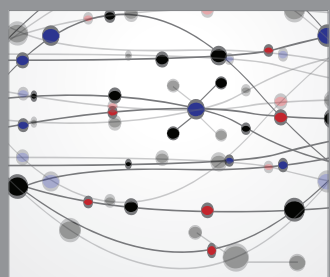

The Scientific World Journal
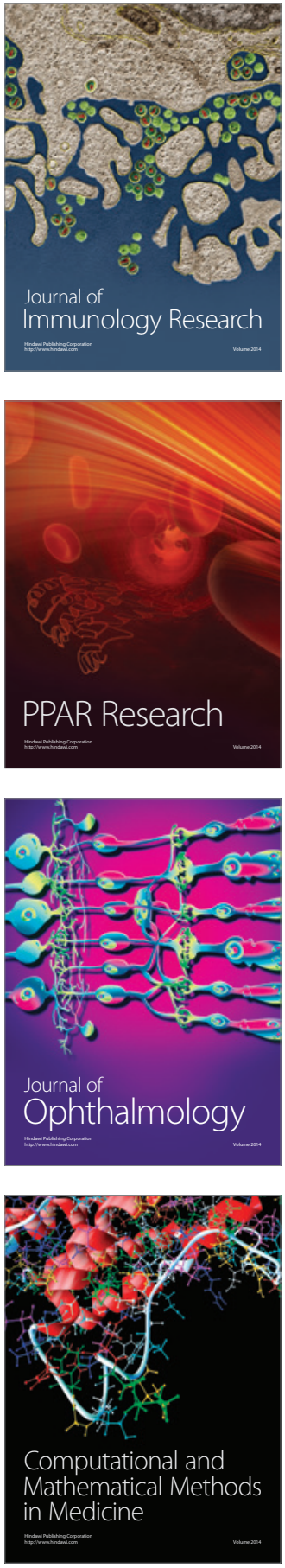

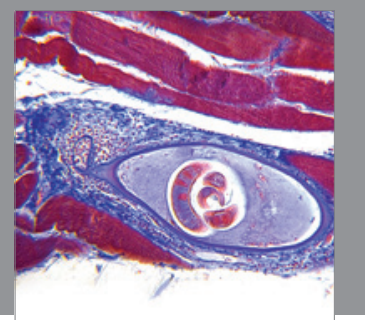

Gastroenterology

Research and Practice
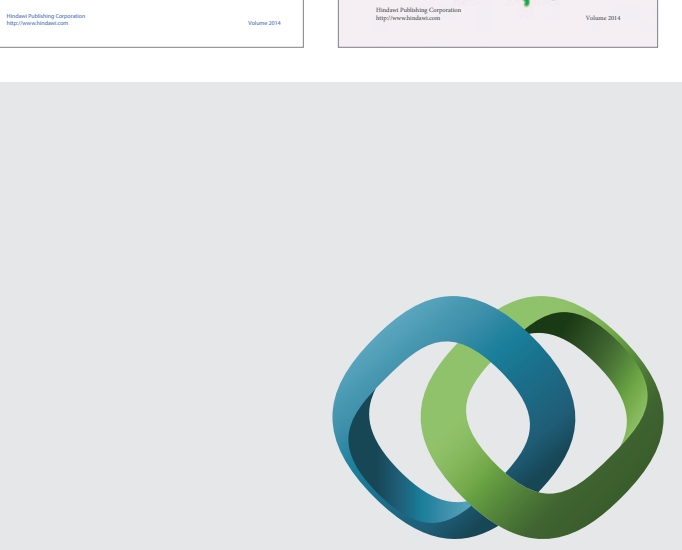

\section{Hindawi}

Submit your manuscripts at

http://www.hindawi.com
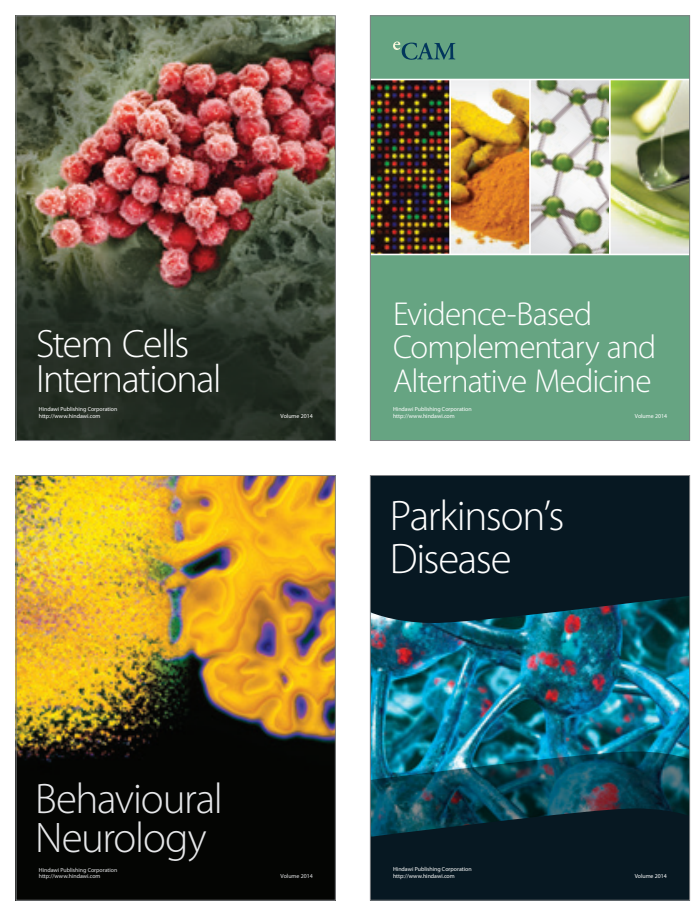

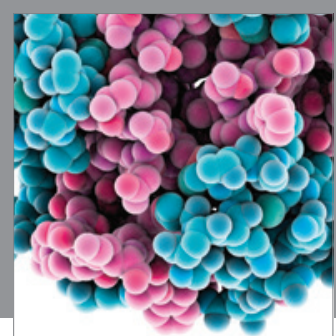

Journal of
Diabetes Research

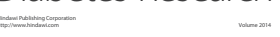

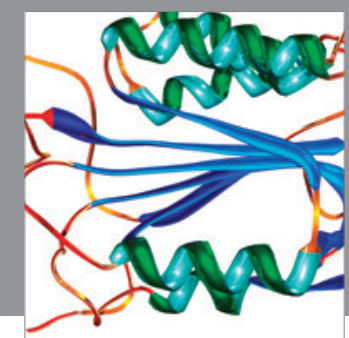

Disease Markers
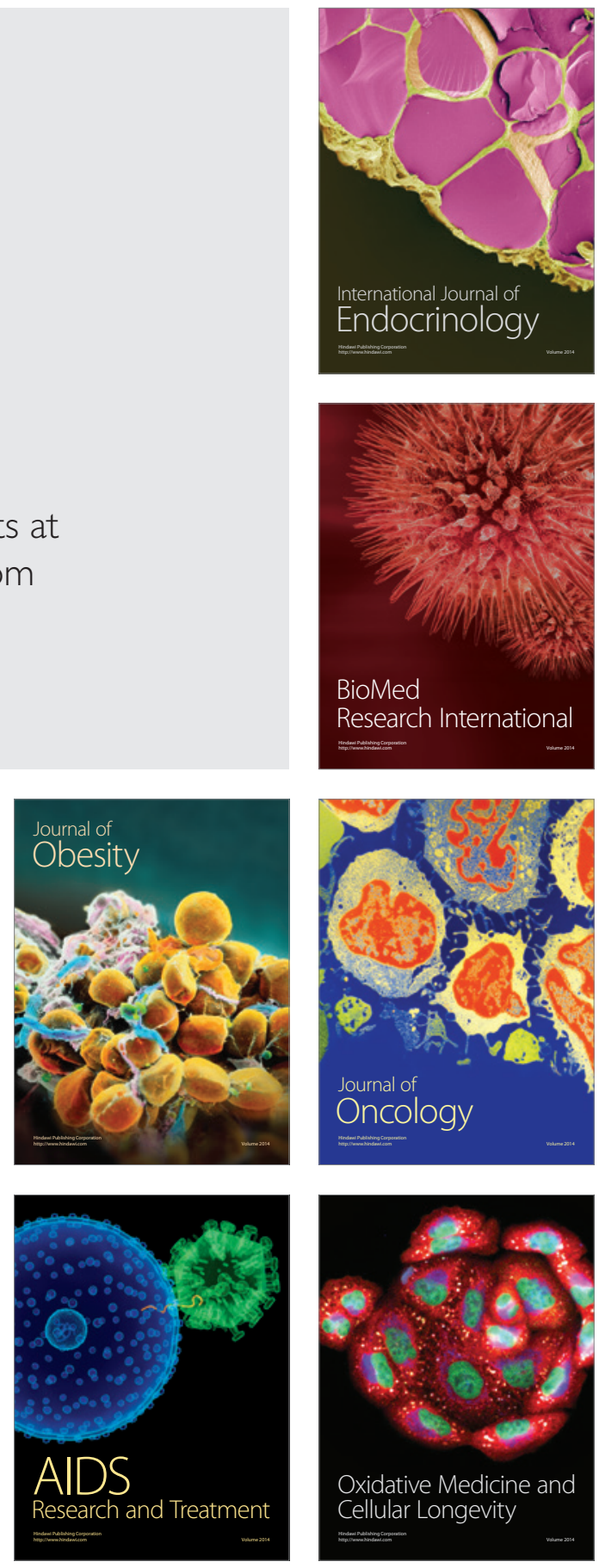